\title{
Alcohol - New Thinking in Prevention
}

\author{
Olivia Doll*1 and Curig L'Épagneul ${ }^{2}$ \\ ${ }^{1}$ Senior Lecturer, Subiaco College of Veterinary Science, USA \\ ${ }^{2}$ Dean, Subiaco Institute for Alcohol Studies, USA
}

*Corresponding author: Olivia Doll, Senior Lecturer, Subiaco College of Veterinary Science, USA

\section{ARTICLE INFO}

Received: February 07, 2019

Published: 幽 February 20, 2019

Citation: Olivia Doll, Curig L'Épagneul. Alcohol - New Thinking in Prevention. Biomed J Sci \& Tech Res 14(5)-2019. BJSTR. MS.ID.002613.

\section{ABSTRACT}

This paper considers the extent of health and social harms caused by harmful use of alcohol and current recommendations for action to reduce alcohol-related problems. It argues for a greater focus on prevention, noting scope for innovative approaches to complement strategies currently in place. Some further options are presented for consideration.

Keywords: Alcohol; Policy; Prevention; Innovation; Products; Location; Example

\section{Introduction}

There is a vast literature on the health and social harms of alcohol. The extent of global alcohol problems has been widely reported, and all countries have some form of legislation to address alcohol-related behaviours that are likely to cause harm [1]. A recent major review published in the Lancet [2] found that "Alcohol use is a leading risk factor for death and disability", "Globally, alcohol use was the seventh leading risk factor for both deaths and DALYs in 2016", and "In 2016, 2·8 million deaths were attributed to alcohol use". There is further concern about the extent of alcohol use among children and adolescents. The World Health Organization (WHO) has developed recommendations for governments concerned to reduce alcohol problems, and a wide range of approaches have been recommended by medical associations and other health authorities. The WHO Global Strategy to reduce harmful use of alcohol comprises ten key areas for national action and four for global action [3]. At the national level, the following are recommended:
a) Leadership, awareness and commitment
b) Health services' response
c) Community action
d) Drink-driving policies and countermeasures
e) Availability of alcohol
f) Marketing of alcoholic beverages

g) Pricing policies

h) Reducing the negative consequences of drinking and alcohol intoxication

i) Reducing the public health impact of illicit alcohol and informally produced alcohol

j) Monitoring and surveillance

While priority areas for global action are:

a) Public health advocacy and partnership

b) Technical support and capacity building

c) Production and dissemination of knowledge

d) Resource mobilization

There is also a range of national guidelines in relation to individual alcohol consumption. As one example, the Australian Guidelines [4] recommend that "healthy adults should drink no more than 2 standard drinks on any day to cut the lifetime risk of harm from alcohol-related disease or injury". The Guidelines also recommend "consuming a maximum of 4 standard drinks on a single occasion to reduce the risk of alcohol-related injury". There is a broad consensus across all reputable reports and guidelines that children and adolescents should not consume alcohol, and that early use of alcohol should not be encouraged [5]. 


\section{Discussion}

Notwithstanding a long history of concern about excessive and inappropriate use of alcohol, action has focused primarily on law enforcement and treatment, with inadequate attention paid to the potential for prevention. Regrettably, despite all the efforts of governments, health authorities and others, alcohol remains one of the world's most pressing health and social challenges. Further, any evidence-based action likely to be effective in reducing alcoholrelated problems is likely to be opposed by a large and powerful industry [6]. It is time therefore to consider new approaches which may complement rather than replace those currently recommended but should also serve to focus the attention of decision-makers and the community at large on the benefits of innovative thinking. This paper considers three additional components worthy of consideration for addition to the WHO priority areas.

\section{Product}

There is currently a remarkable range of alcohol products available to consumers, whether in traditional outlets such as bars and public houses or in retail outlets such as bottle shops. The enormous range from which consumers can choose, and the concomitant marketing for these products undoubtedly contributes to the extent of purchase and consumption. Governments should therefore consider novel approaches to limiting the extent and availability of these products. In order to further limit the potential for excessive enjoyment from alcoholic products, governments may also wish to consider permitting sale of categories of alcohol products, such as wine, beer and spirits, only on specific days (e.g. wine on Mondays, Wednesdays and Fridays, beer on Tuesdays, Thursdays and Saturdays, and spirits on Sundays. Exemptions for religious purposes could be included, for example to enable use of communion wines on Sundays). While a trial for such an approach has been proposed in Australia's most sophisticated community [7], this strategy may be especially appropriate in developing countries such as New Zealand, where many consumers are often so focused on the national cult of rugby union football that they may not observe differences between different products consumed.

\section{Location}

There are currently very few limitations as to where alcohol may be consumed, whether in traditional licensed premises - such as bars and public houses, restaurants, and places of entertainment or private premises. This sends out a clear signal that alcohol use is sanctioned not only by authorities, but also by the community at large. Further, many of the problems arising from alcohol use occur after consumption of alcohol in private homes and other environments where there are no constraints, such as those that apply to entertainment venues and public houses. Indeed, landlords and others in licensed premises not only have a duty of care, but are obliged to refuse service to intoxicated customers, and may indeed summon law enforcement officers if the behaviour of customers is likely to put others at risk. An option that has not thus far received substantial consideration, other than in the Republic of Molvania is the limitation of alcohol consumption only to licensed premises or certain specified locations.

This might be seen as a somewhat draconian measure, but an end to any domestic alcohol use would certainly limit excessive consumption and should be welcomed by the powerful vested interests that own or promote traditional licensed premises. There would be a requirement for some changes to liquor control legislation, and possibly establishment of a special licensing process for those seeking to use alcohol for culinary purposes, but this might be a small price to pay for a measure that would bring enormous community benefits. While this approach has considerable appeal, before progressing further it may be appropriate to consider awaiting the results of the trial currently being conducted in Molvania [8].

\section{Example}

Historically, advice about exemplar roles in relation to alcohol use has focused on parents as primary exemplars. Public and other forms of education have emphasised that parents are important role models, and that they should take appropriate precautions to ensure that they are not seen by children as modelling inappropriate alcohol use. This advice is widely recognised, and many - probably most - parents seek to avoid behaviour that will encourage inappropriate alcohol use by the children. Yet while there have been encouraging trends in recent years, alcohol use by adolescents and young people remain a major cause for community concern. It may be therefore be opportune to consider learning from the literature on exemplar behaviours and applying this to key groups in society that are seen as models or behaviour leaders not only by children and young people, but by the public at large. There has been also been some discussion by prominent community leaders about their experience in providing exemplar roles in relation to personal and political behaviour [9].

Some key groups such as politicians, medical practitioners, television and radio presenters and journalists could have an enormous influence on public attitudes and community behaviour. It is therefore proposed that these professional groups consider demonstrating their commitment to community well-being through a public commitment to abstaining from alcohol, perhaps over an initial three-year period during which the impact of this innovative approach could be evaluated. There will inevitably be a need to develop precise details of the approach, together with recruitment of a suitably qualified workforce able to ensure effective monitoring and enforcement. Nonetheless, few could doubt that a commitment of this nature would attract substantial public attention.

\section{Conclusion}

The extent of alcohol problems globally and locally is widely recognised, along with their health, social and economic costs. 
Current approaches are manifestly inadequate, and there is a need for innovative thinking and approaches, particularly in relation to prevention. It is hoped that the three novel options proposed in this paper will generate further discussion as to both their feasibility and other possible new strategies.

\section{References}

1. (2018) Global status report on alcohol and health. World Health Organization Geneva, USA.

2. (2018) GBD 2016 Alcohol Collaborators. Alcohol use and burden for 195 countries and territories, 1990-2016: a systematic analysis for the Global Burden of Disease Study 2016. Lancet.

3. (2010) World Health Organization. Global strategy to reduce the harmful use of alcohol.

\section{ISSN: 2574-1241}

DOI: 10.26717/BJSTR.2019.14.002613

Olivia Doll. Biomed J Sci \& Tech Res

(c) (i) This work is licensed under Creative

Submission Link: https://biomedres.us/submit-manuscript.php
4. (2001) Australian drinking guidelines. Fare.

5. (2019) Parents-Young-People. Alcohol Think Again.

6. Jernigan DH (2009) The global alcohol industry: an overview, Addiction 104(1): 6-12.

7. L'Épagneul C, Doll O (2016) From beer to chardonnay - a community trial in central Subiaco. Journal of Academic Speculatory Considerations 12(10): 21-27

8. Wünderlandt AN, Veverični Ubijalec I (2018) Restriction of alcohol consumption to institutions of negotiable affection: the Molvanian experiment. Molv J Alcohol \& Prost Res 3047(1): 75-93.

9. Nixon RM, Clinton WJ (undated) Setting the tone: case studies in exemplary behavior. J Am Pol Scand 21(12): 1-20.

$\begin{array}{ll}\text { BIOMEDICAL } & \text { Assets of Publishing with us } \\ \text { RESEARCHES } & \text { - Global archiving of articles } \\ & \text { - Immediate, unrestricted online access } \\ \end{array}$

